\title{
Aplicação de Software Educacional KBRUCH no ensino/prática de operações com números fracionários
}

\author{
Dárley D. de Almeida
}

\author{
Departamento de Ciência da Computação \\ Universidade do Estado do Mato Grosso (UNEMAT) - Alto Araguaia, MT - Brasil \\ \{ darleydalmeida@gmail.com
}

\begin{abstract}
New information and communication technologies bring in their path an innovative perspective, which has as its basic characteristic the interrelationship between research, training and practice. In this paper, we present the results of the application of KBruch free software in the state public high school classroom, with the objective of improving the students' performance regarding the content of the arithmetic operations related to the fractionation indexes and use the benefits of the free software in question in the math teaching process.
\end{abstract}

Resumo. Novas tecnologias de informação e comunicação trazem em sua trajetória uma perspectiva inovadora, que tem como característica básica a inter-relação entre pesquisa, formação e prática. Neste trabalho são apresentados os resultados da aplicação do software livre KBruch em sala de aula do segundo ano do ensino médio da rede pública estadual, com objetivo de promover melhora no desempenho dos alunos com relação ao conteúdo de operações aritméticas envolvendo números fracionários e identificar os benefícios do software livre em questão no processo de ensino aprendizagem de Matemática.

\section{Introdução}

As configurações atuais de ensino ainda são quase as mesmas de décadas atrás, tendo tido um avanço quase insignificante na mudança comportamental na relação aluno/professor. Por esse motivo inúmeros professores buscam formas de inovar em sala de aula tornando as aulas mais atrativas e dinâmicas, contudo empregar as mesmas ações é mais complicado quando o assunto é a área de Exatas, uma vez que suas aplicações práticas demandam diferentes recursos para serem observadas. É fato que estamos rodeados de computadores, e, inegavelmente, poucos profissionais hoje não estão envolvidos com o manuseio de computadores, mesmo que apenas como usuários de aplicações específicas. Não se pode afirmar que apenas a produção de conteúdos educacionais utilizando ferramentas tecnológicas consegue garantir que o indivíduo aprenda. Entretanto, o uso da tecnologia pode efetivamente apoiar e enriquecer as atividades educacionais desde que sejam utilizadas de maneira adequada.

O uso de software educacional é uma sugestão fundamentada nas Tecnologias da Informação e Comunicação (TICs), que tem em vista gerar o método de ensino aprendizagem para o ensino de tópicos matemáticos. Deste modo, sendo empregado com a ajuda do docente de forma delineada, requer ao educando se transformar num indivíduo ligado na edificação do conhecimento. Determinados softwares podem apoiar $\mathrm{o}$ 
processo de construção do conhecimento, assim sendo, são capazes de ser usados como auxiliares no método de ensino aprendizagem, todavia, a escolha de um software educacional está diretamente ligada aos objetivos a serem alcançados. Assim, cabe ao professor decidir sobre a qualidade técnica e curricular do produto, baseado em sua capacitação na utilização desses recursos para a transmissão dos conteúdos curriculares [1].

O objetivo principal desse trabalho é apresentar a aplicação do software livre KBruch em sala de aula do segundo ano do ensino médio da rede pública estadual, com objetivo de promover melhora no desempenho dos alunos com relação ao conteúdo de operações aritméticas envolvendo números fracionários.

O KBruch é um software livre de exercícios matemáticos envolvendo frações e porcentagens [2]-[4]. É um dos softwares que integra o projeto/pacote educacional KDEdu [5], suíte de softwares livres educacionais distribuídos para o sistema operacional Linux. O pacote KDEdu, e, por conseguinte, o software KBruch, foram desenvolvidos e distribuídos para uso tanto como aplicações desktop quanto web.

O software KBruch possui exercícios de soma, subtração, multiplicação e divisão de frações, fatoração, comparação de valores e conversão. Ao utilizar o KBruch, o usuário vai ter uma tarefa para resolver, e, após concluída esta, o programa faz a verificação do resultado e são apresentadas estatísticas a respeito do desempenho do usuário, transformando os dados em porcentagens de erros e acertos. É um excelente programa para prática de exercícios e teste do conhecimento dos alunos, despertando seu interesse e trabalhando de forma mais dinâmica com a Matemática [6]. Ao iniciar a execução do aplicativo, são apresentados dois tipos de atividades: o Exercício, que é o modo de treinamento, e a Aprendizagem, onde o usuário poderá acompanhar explicações a respeito do conteúdo de frações.

\section{Metodologia}

Para realização deste trabalho, foi tomado como grupo amostral uma turma do Segundo Ano do Ensino Médio de Colégio da Rede Pública Estadual do Município de Santa Rita do Araguaia - GO. A turma é composta por vinte e um alunos com faixa etária entre 15 e 17 anos de idade, sendo destes, nove meninos e doze meninas. Foi identificado que grande parte dos alunos da turma observada possuíam considerável dificuldade durante a realização de exercícios matemáticos envolvendo operações com números fracionários. Em atividade para aferição inicial e registro do nível de desempenho dos alunos quanto a tais tipos de atividades, aproximadamente $81 \%$ da turma (dezessete alunos) obtiveram resultado abaixo da média, ou seja, obtiveram notas inferiores a seis inteiros.

Os alunos foram divididos em três grupos de sete alunos (em função da capacidade do laboratório de informática de modo a permitir que cada aluno utilizasse um computador de modo individual), e, no primeiro dia cada grupo utilizou o laboratório por aproximadamente cinquenta minutos divididos entre familiazrização com o software, navegação no modo de aprendizagem, navegação no modo exercício, e realização de exercício com tomada de tempo. Na aula seguinte, os alunos foram novamente divididos em três grupos de sete alunos, e cada grupo utilizou o laboratório por aproximadamente vinte e cinco minutos, sendo os cinco minutos finais de cada grupo, novamente utilizado para realização de uma mini competição de desempenho, em seguida, os alunos com 
desempenho menor que $50 \%$ foram convidados a retornar para o laboratório, onde fizeram uma nova bateria de exercícios, intercalando os modos de uso "aprendizagem" e "Exercícios", durante aproximadamente vinte e cinco minutos.

Em avaliação para aferição da melhora de desempenho, o número de alunos que obtiveram notas inferiores a seis inteiros, ou seja, abaixo da média permitida, caiu de aproximadamente $81 \%$ (dezessete alunos) na avaliação inicial, para aproximadamente $24 \%$ (cinco alunos) na avaliação final. Cabe ressaltar também que a nota média da sala na avaliação inicial foi aproximadamente cinco inteiros e dois décimos $(5,2)$ enquanto, na avaliação final, a média de notas foi de aproximadamente sete inteiros e nove décimos $(7,9)$.

\section{Considerações Finais}

O uso do software livre KBruch mostrou-se bastante promissor como ferramenta auxiliar no processo de ensino-aprendizagem de operações algébricas envolvendo números fracionários para o grupo observado. No cenário apresentado, o uso da ferramenta computacional citada promoveu melhora do desempenho de praticamente todos os alunos, uma vez que a nota média da sala foi elevada em quase três pontos e o número de alunos com notas abaixo de seis inteiros foi reduzido em aproximadamente setenta porcento. Em trabalhos futuros pretende-se estender a aplicação dos testes em turmas da mesma série do Ensino Médio, e avaliar comparativamente o desempenho de turmas que estudaram com e sem o auxílio do software livre KBruch.

\section{REFERÊNCIAS}

[1] B. S. TOLEDO, O uso de softwares como ferramenta de ensino aprendizagem na educação do ensino médio/técnico no Instituto Federal De Minas Gerais. Dissertação de Mestrado. Curso de Mestrado Profissional em Sistemas de Informação e Gestão do Conhecimento. Universidade FUMEC, 2014.

[2] C. J. PRINCIVAL e J. F. C. BUGHAY, Softwares Educacionais: algumas possibilidades disponibilizadas pelo PRD e PROINFO. III Simpósio Nacional de Ensino de Ciência e Tecnologia, 2012.

[3] E. M. SLOMP, Análise da ferramenta KBRUCH para as aulas de matemática do 7o ano do Ensino Fundamental em uma escola da rede municipal da cidade de Timbó - SC. Monografia de Conclusão de Curso. Curso de Especialização em Educação na Cultura Digital. Universidade Federal de Santa Catarina, 2016.

[4] F. B. B. SANTOS, A. TEDESCO, e B. FURTADO, Mapeamento de Jogos Educacionais. Revista Espaço Pedagógico, vol. 19, no. 2, Passo Fundo - RS, pp. 353-363, 2012.

[5] R. S. MELO e B. G. B. NEVES, Avaliação de Software Livre Educacional: investigando o potencial de utilização do KDEDU nos anos iniciais do Ensino Fundamental. Texto Livre: Linguagem e Tecnologia, pp. 90-106, 2013.

[6] S. STEIN e A. M. MAHFOUF, Manual do KBruch. Disponível em: < https://www.mundoubuntu.com.br/images/PDFs/kbruch.pdf $>$. Acesso em: 14 set. 2019. 